\title{
PERANCANGAN SURFACE DESIGN PAPER CUP CAFE DARI MOTIF UKIRAN LAPIEH JARAMI MINANGKABAU
}

\author{
Elsa Lumban Gaol ${ }^{1}$, Amelia Refiani ${ }^{2)}$, Elma Ahda Safira ${ }^{3)}$ \\ Program Studi Desain Komunikasi Visual, \\ Fakultas Bahasa dan Seni, Universitas Indraprasta PGRI \\ Jl. Nangka No. 58 C, Tanjung Barat, Jakarta Selatan, 12530, Indonesia \\ elsa.lumbangaol9@gmail.com
}

\begin{abstract}
Abstrak
Pada perancangan surface design ini bertujuan melestarikan wujud kebudayaan pada produk modern yaitu paper cup pada cafe. Tulisan ini merupakan hasil dari penelitian yang dilakukan berdasarkan literatur yang ada, disamping itu minimnya pengetahuan masyarakat tentang ukiran motif Lapieh Jarami. Maka diperlukan media yang dapat mengidentifikasi bentuk dari motif ukiran Lapieh Jarami. Jenis tipografi yang digunakan adalah jenis huruf Balinese Family. Menggunakan warna hitam, kemudian bagian latar belakang menggunakan warna kuning. Proses perancangan surface design ini menggunakan perangkat lunak adobe illustrator, adobe photoshop, dan corel draw. Penggunaan media paper cup diharapkan memberikan efektifitas dalam melestarikan motif corak untuk masyarakat modern.
\end{abstract}

Kata Kunci: Perancangan, Gelas Kertas, Motif, Ukiran, Lapieh Jarami

\begin{abstract}
The design of this surface design aims to preserve the cultural form of modern products, namely the paper cup at the cafe. This paper is the result of research conducted based on existing literature, besides that the lack of public knowledge about the carving of the Lapieh Jarami motif. So we need a media that can identify the shape of the Lapieh Jarami carving motif. The type of typography used is the Balinese Family font. Use black, then the background uses yellow. The process of designing this surface design using Adobe illustrator software, Adobe Photoshop, and Corel Draw. The use of paper cup media is expected to provide effectiveness in preserving pattern motifs for modern society.
\end{abstract}

Keywords: Design, Paper Cup, Motif, Carving, Lapieh Jarami

Correspondence author: Elsa Lumban Gaol, elsa.lumbangaol9@gmail.com, Jakarta, and Indonesia

This work is licensed under a $C C-B Y-N C$ 


\section{PENDAHULUAN}

Indonesia memiliki 34 provinsi dengan ribuan bahasa disetiap kota dan daerahnya, jumlah provinsi yang begitu banyak, membuat kebudayaan di Indonesia menjadi beragam serta mempunyai keunikannya masing - masing, salah satunya yang terunik adalah Sumatera Barat.

Telah teridentifikasi bahwa ada delapan suku yang mendiami tanah Sumatera Barat, yaitu Suku Mentawai, suku Kubu, suku Sakai, suku Bonai, suku Melayu, suku Talang Mamak, suku Kerinci dan suku Minangkabau sebagai penduduk Sumatera Barat yang paling dominan, karena itu sangat wajar jika Provinsi Sumatera Barat dikenal lewat suku Minangkabau. Adapun berbagai bentuk kebudayaan Minangkabau, salah satu diantaranya adalah seni ukir.

Seni Ukir merupakan bagian dari arsitektur Minangkabau yang sungguh menarik bersamaan dari yang mana setiap bentuk ukirannya mengandung nilai - nilai makna yang tersirat dalam kehidupan. Penempatan ukiran tradisional Minangkabau ini tidaklah sembarangan, setiap motif ukiran memiliki makna dan fungsi yang berbeda yang akan mempengaruhi penempatannya (Isnan, H. \& Rohmiyati, Y, 2016: 3).

Motif ukiran Minangkabau pada umumnya diterapkan pada bangunan seperti rumah gadang atau rumah adat, istana kerajaan, balai adat, masjid, rangkiang, dan lain-lain, baik untuk bidang kecil maupun pada bidang besar. Selain itu juga diterapkan pada beberapa peralatan sehari-hari misalnya pada peralatan upacara, rumah tangga, alat pertanian, alat permainan dan sebagainya (Khairuzzaky, 2018: 55).

Namun, seiring dengan berjalannya waktu dan perkembangan zaman, tradisi kebudayaan termasuk seni ukir telah terlupakan oleh masyarakat Minangkabau. Hal ini mendasari penulis tertarik untuk mengambil permasalahan yang berkaitan dengan pelestarian pengetahuan seni ukir pada kebudayaan Minangkabau. Uniknya cara penulis untuk melestarikan seni ukir ini tidak menggunakan media bangunan sebagai cara penambah pengetahuan masyarakat melainkan menggunakan paper cup sebagai inovasi produk modern yang digunakan untuk minum di cafe.

Berdasarkan hasil literatur yang ada, penulis ingin mencoba melestarikan kebudayaan Minangkabau melalui surface design paper cup sebagai produk modern yang digunakan untuk peralatan minum di cafe. Harapannya dengan membuat surface design paper cup ini, dapat membuat masyarakat meningkatkan pengetahuannya tentang Motif Ukir di Minangkabau, khusunya pada Motif Lapieh Jarami.

\section{METODE PENELITIAN}

Metode dalam arti luas, menurut Bogdan dan Taylor (1993: 25) adalah "proses, prinsipprinsip dan prosedur yang dipakai dalam mendekati persoalan dan usaha mencari jawabannya."

Penelitian kualitatif oleh Cottle dalam Bogdan dan Tailor (1993: 36) menyatakan: "sebuah metode penelitian yang mendasar karena mengunjungi masyarakat, mendengarkan dan berbicara dengan mereka dan memungkinkan pembicaraan itu berjakan sebagaimana mereka kehendaki, karena itu seseorang (peneliti), dan perasaan peneliti dirangsang oleh tutur kata, sejarah dan catatan-catatan orang yang diteliti”.

Studi literatur merupakan pencarian sumber-sumber relevan yang berkaitan dengan pembahasan secara tertulis.Dalam penelitian ini, penulis menggunakan metode penelitian kualitatif, dengan teknik pengumpulan data studi literatur.

\section{HASIL DAN PEMBAHASAN}

Sebelum masuk ke tahap perancangan desain, berikut landasan teori untuk memperkuat hasil rancangan yang dibuat.

\section{Desain Komunikasi Visual}

Desain komunikasi visual adalah keilmuan terapan terintegrasi yang mengkaji konsep komunikasi dan ungkapan kreatifnya, beserta teknik dan medianya, untuk menyampaikan pesan dan gagasan secara visual sehingga pesan terterima dan atau berfungsi sebagaimana tujuannya (Waluyanto, 2005: 45). 
Desain komunikasi visual memiliki pengertian secara menyeluruh, yaitu rancangan sarana komunikasi yang bersifat kasat mata (Sanyoto, 2006:8).

Desain Komunikasi Visual adalah bentuk komunikasi melalui media untuk menyampaikan ide, gagasan, dan pesan dengan menggunakan elemen-elemen visual dengan tujuan untuk mempengaruhi orang lain.

\section{Lapieh Jarami}

Lapiah jarami adalah jalinan dari batang padi yang telah dipotong sehingga membentuk suatu ikatan yang kuat. Motif ini hampir sama bentuknya dengan motif lapiah ampek. Motif ini melambangkan adanya rasa persaudaraan, persatuan serta tidak sombong, dapat menempatkan diri di mana saja serta disenangi oleh orang banyak (Khairuzzaky, 2018: 55).

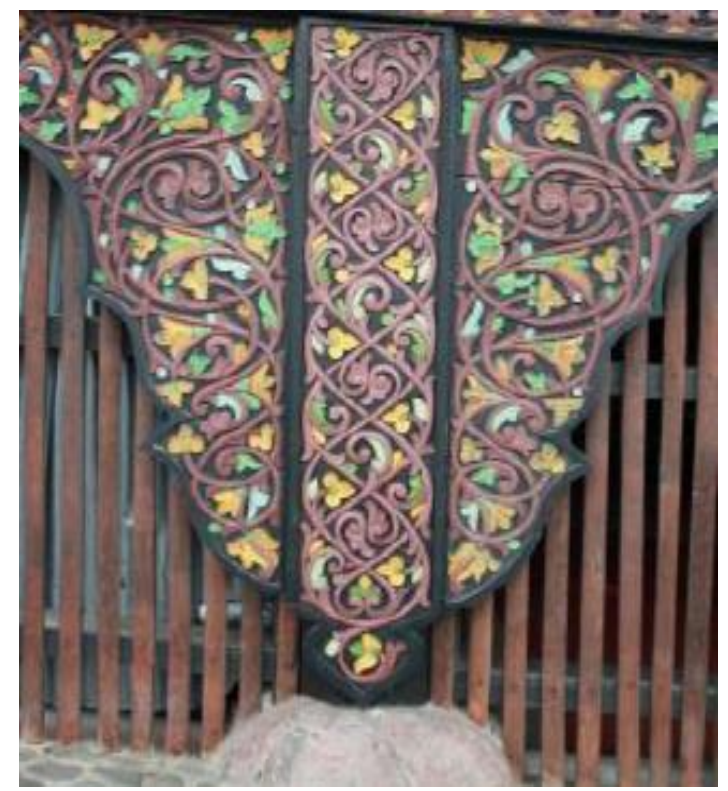

Gambar 1 Motif Ukir Lapieh Jarami pada Kaki Sumber: Khairuzzaky, 2018: 61

Motif Lapeh Jarami terdapat pada bagian salangko/kaki Istana Basa Pagaruyung yang di dominasi oleh ukiran di bidang yang besar.

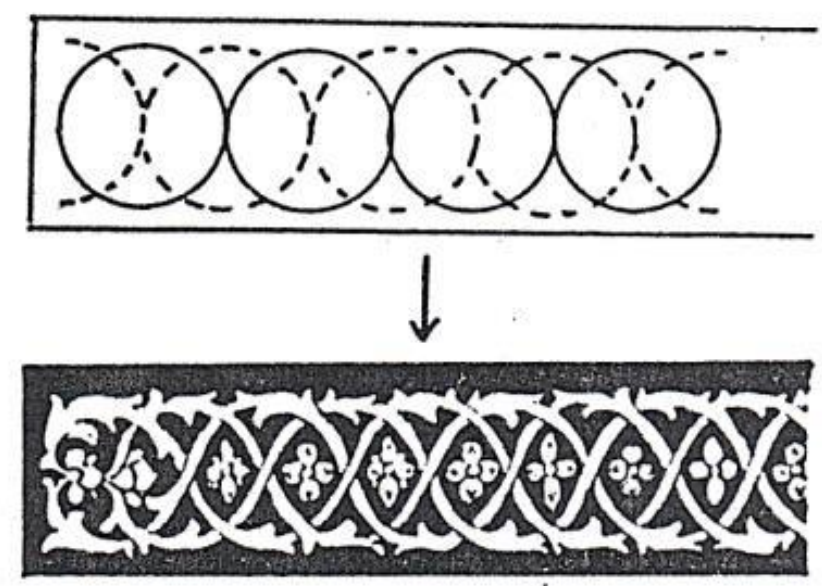

Gambar 2 Pola Motif Lapieh Jarami Sumber: Usman, 1980. 
Adapun Lapieh Jarami adalah anyaman yang terbuat dari jerami. Melihat bentuk yang terdapat pada motif ini, maka unsur anyaman ini memang terlihat jelas, oleh karena itu nomenclature nya diambilkan dari nama motif Lapieh. Jarami (Anyaman Jerami). Melihat dari polanya dapat dikatakan sama dengan pola aka duo gagang yang berganda. Hal ini dapat diperhatikan pada bagan tertera diatas.

Kemudian terdapat makna simbolis pada Ukiran Lapieh Jarami di Kaki Istana yang tertera dibawah ini:

Bilalang dapek dek manuai

Lapiah balapiah batang padi

Tapijak dek tapak manuju lampok

Bakeh lalu tampek bapijak

Tanah lambok, bungin kok rawang

Nak samat padi ka lampok

Elok nampak dek mato

Indah nan lalu kahati

Timbua kalukih papan tuai

Manjala katumbuang sitinjau lauik

Dek arih tukang nan utuih

Lah jadi ukia sampai kini

Penyesuaian hidup dengan lingkungan diungkapkan dengan pepatah-petitih:

Dimana bumi dipijak, di sinan langik dijunjuang

(Dimana bumi dipijak, di sana langit dijunjung)

Artinya dimana pun kita hidup aturan orang setempat itulah yang dipakai.

Berikut warna yang terkandung pada Motif Lapieh Jarami:

Tabel 1. Makna Warna Ukiran menurut M. Sayuti Dt. Rajo Penghulu

\begin{tabular}{|l|l|l|}
\hline Warna & $\begin{array}{l}\text { Nama } \\
\text { Warna }\end{array}$ & Arti Warna \\
\hline Hitam & $\begin{array}{l}\text { Melambangkan kebesaran nagari Luhak } \\
\text { Limo Puluah Koto maka marawa nya } \\
\text { berwarna hitam disebelah luar. }\end{array}$ \\
\hline & Kuning & $\begin{array}{l}\text { Melambangkan kebesaran nagari Luhak } \\
\text { Tanah Datar. Jika acara di wilayah adat } \\
\text { Luhak Tanah Datar, maka marawanya } \\
\text { berwarna kuning disebelah luar. }\end{array}$ \\
\hline merah & $\begin{array}{l}\text { Melambangkan kebesaran nagari Luhak } \\
\text { Agam. Jika acara di wilayah adat Luhak } \\
\text { Agam, maka marawanya berwarna merah } \\
\text { disebelah luar. }\end{array}$ \\
\hline
\end{tabular}

\section{Proses Perancangan}

Berdasarkan literatur, berikut representasi Lapieh Jarami ketika divisualisasikan. 


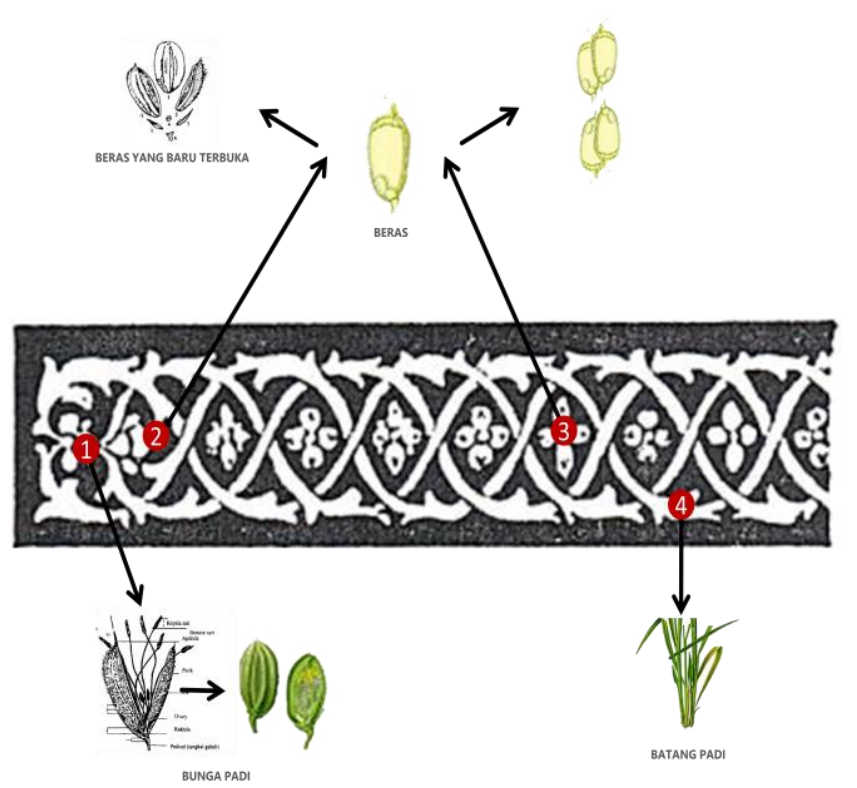

Gambar 3 Visualisasi Motif Lapieh Jarami Sumber: Dokumen Pribadi

Berdasarkan hasil analisa penulis mendapati identitas visual yaitu warna, huruf serta raut bidang pada Lapieh Jarami.

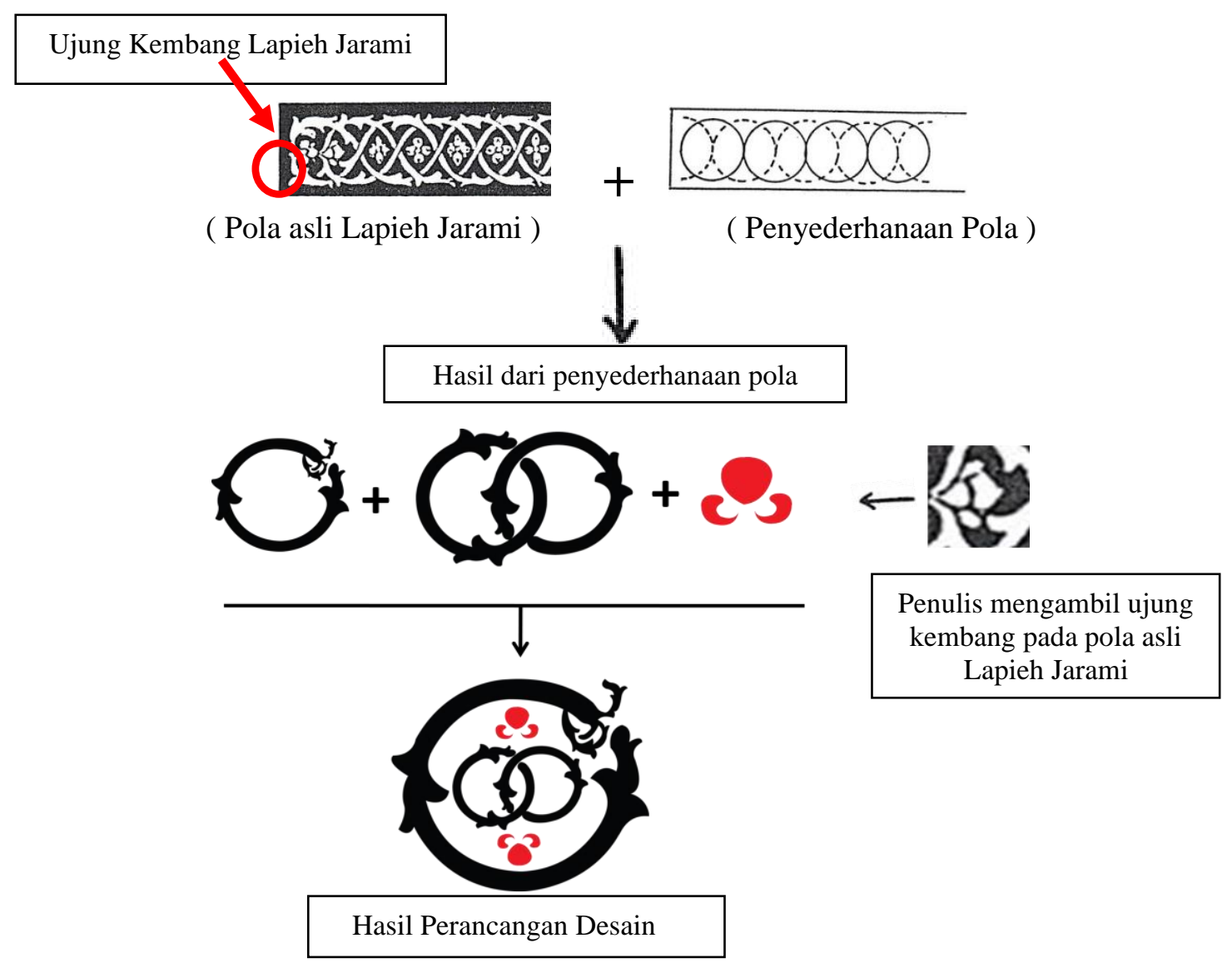

Gambar 4 Perancangan Desain Motif untuk Paper Cup Sumber: Dokumen Pribadi 
Penggunaan warna pada surface design paper cup disesuaikan dengan warna yang terdapat pada lapieh jarami, agar tidak menghilangkan makna dan identitas dari motif ukiran sesungguhnya.

Tabel 1. Makna Warna Ukiran menurut M. Sayuti Dt. Rajo Penghulu

\begin{tabular}{|l|l|l|}
\hline Warna & $\begin{array}{l}\text { Nama } \\
\text { Warna }\end{array}$ & Arti Warna \\
\hline Hitam & $\begin{array}{l}\text { Melambangkan kebesaran nagari Luhak } \\
\text { Limo Puluah Koto maka marawa nya } \\
\text { berwarna hitam disebelah luar. }\end{array}$ \\
\hline \multirow{7}{*}{ Kuning } & $\begin{array}{l}\text { Melambangkan kebesaran nagari Luhak } \\
\text { Tanah Datar. Jika acara di wilayah adat } \\
\text { Luhak Tanah Datar, maka marawanya } \\
\text { berwarna kuning disebelah luar. }\end{array}$ \\
\hline & $\begin{array}{l}\text { Melambangkan kebesaran nagari Luhak } \\
\text { Agam. Jika acara di wilayah adat Luhak } \\
\text { Agam, maka marawanya berwarna merah } \\
\text { disebelah luar. }\end{array}$ \\
\hline
\end{tabular}

Font yang digunakan untuk perancangan surface design paper cup cafe dari motif ukiran lapieh jarami minangkabau adalah Balinese Family, dikarenakan karakteristik huruf sesuai dengan konsep penggambaran budaya indonesia dengan jenis huruf dekoratif.

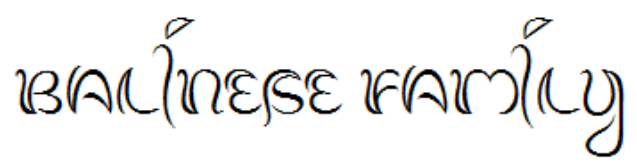

A B C

wox $x$

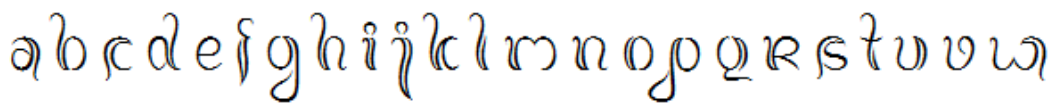

$x y \&$

\section{0 \\ !@\#\$^*()_\{\}}

Gambar 5 Font Balinese Family

Sumber: Dokumen Pribadi 
Paper cup atau gelas kertas adalah kemasan minuman dengan bentuk gelas dengan bahan kertas food grade berlaminasi. Modern ini paper cup mulai digemari para pebisnis kuliner yang khususnya menjual produk minuman karena kepraktisannya dan mempermudah penyiapan untuk pengemasan penjualan produk minuman siap saji. Dengan berbahan kertas yang ramah lingkungan, produk ini diperbincangkan para pecinta lingkungan yang paham akan bahayanya global warning. Untuk itulah mengapa, paper cup menjadi produk modern yang akan digunakan untuk perancangan surface.

Pada perancangan ini, ukuran paper cup yang digunakan yaitu 8 x $16 \mathrm{~cm}$ untuk memudahkan masyarakat menggenggam paper cup dengan mudah.

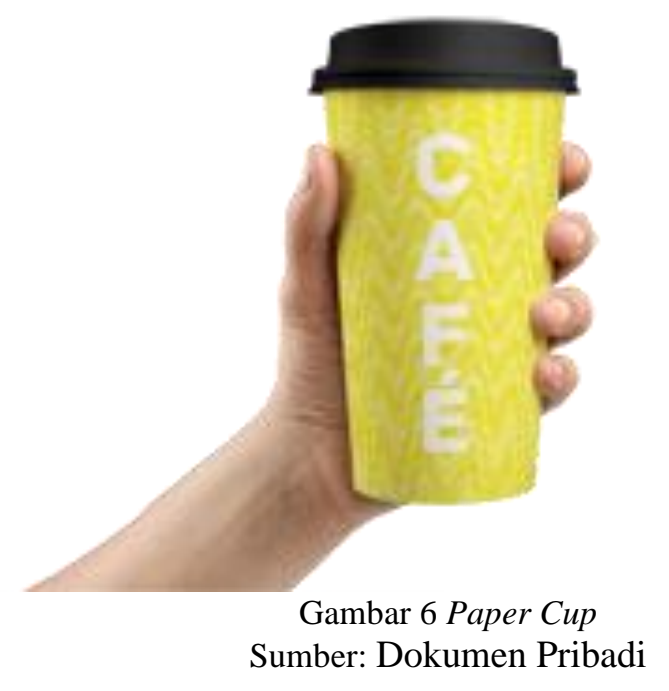

\section{Hasil Perancangan}

Dari hasil perancangan desain telah didapatkan bentuk surface design paper cup pada Lapieh Jerami.

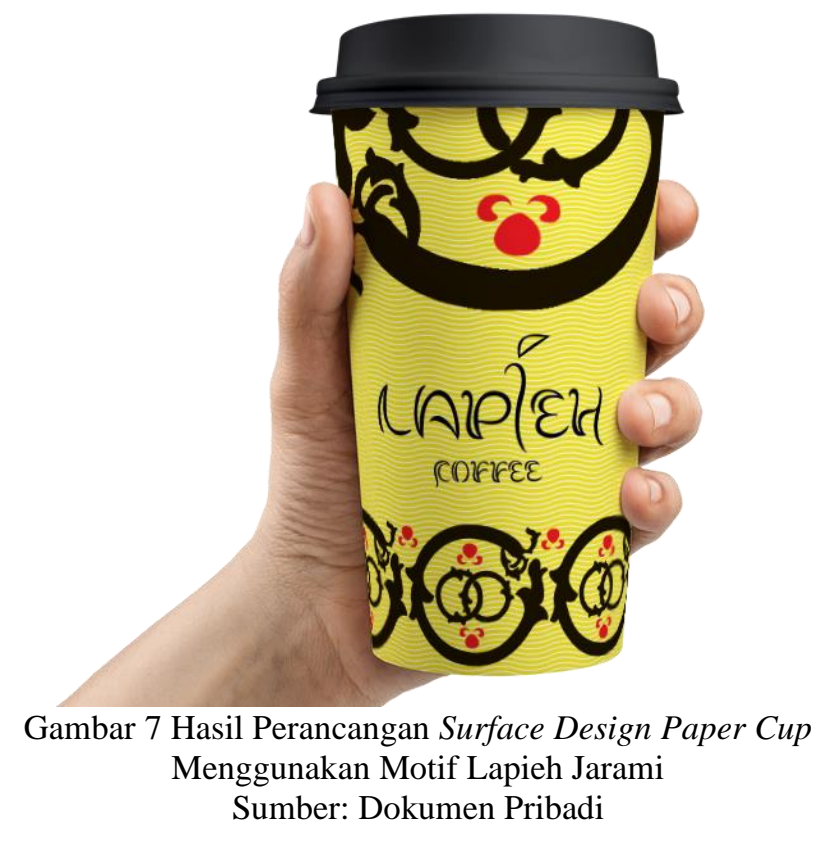

Dengan penggunaan surface design pada paper cup diharapkan mampu melestarikan sekaligus membangun pengetahuan masyarakat terhadap Seni Ukir Minangkabau meskipun bukan dari media bangunan yang seharusnya, melainkan dari media paper cup di cafe. 
Cafe bukan lagi sebagai tempat minum namun telah menjadi ruang publik alternatif yang memiliki beragam fungsi dan berbagai kegiatan seperti: Pertemuan - pertemuan keluarga, pertemuan bisnis, pertemuan politis, termasuk acara - acara lainnya (Damajani, 2008: 142).

Dengan makna :

"Rasa persaudaraan dan persatuan, rendah hati, dapat menempatkan diri di mana saja serta disenangi oleh orang banyak"

Seperti makna yang diatas, paper cup cafe menjadi ranah hubung dengan makna Motif Ukiran Lapieh Jarami.

Sehingga kedua makna paper cup cafe dan Lapieh Jarami saling berkaitan, cafe dengan positioning sebagai tempat menikmati minuman dengan paper cup dalam pertemuan, selaras dengan makna Lapieh Jarami yang memiliki rasa persaudaraan dan persatuan. Penulis pun berharap bahwa kedua makna tersebut juga dapat tersirat pada hubungan sosial setiap orang yang menggunakan paper cup tersebut untuk diminum bersama orang-orang yang dikasihi.

\section{SIMPULAN}

Berdasarkan hasil penelitian diatas dapat disimpulkan bahwa motif ukir Minangkabau mempunyai nilai - nilai dan makna yang tersirat dalam kehidupan, meskipun begitu motif ukir dari Minangkabau telah terlupakan oleh masyarakat sekarang, sehingga sulitnya melestarikan seni ukir Lapieh Jarami. Untuk itu penulis mengharapkan agar masyarakat lebih peka terhadap kebudayaannya sendiri dan dapat melestarikan seni ukir Lapieh Jarami, meskipun cara penulis melestarikan seni ukir tidak menggunakan media bangunan sebagai cara penambah pengetahuan masyarakat, melainkan menggunakan paper cup sebagai inovasi produk modern yang digunakan untuk minum di cafe, karena pada jaman sekarang ini cafe bukan lagi sebagai tempat minum namun telah menjadi ruang publik alternatif yang memiliki beragam fungsi dan berbagai kegiatan dan pertemuan - pertemuan.

\section{DAFTAR PUSTAKA}

Bodgan, R.S.J, Taylor. (1993). Dasar-dasar ppenelitian kkualitatif. Surabaya: Usaha Nasional.

Damajani, R.R.D. (2008). Vernakulisme, informalitas, dan urbanisme: cafe sebagai ekspresi gaya hidup kontemporer. Journal of Visual Art and Design, 2(2), 141-158. Diakses dari http://journals.itb.ac.id/index.php/jvad/article/view/695

Hadi, P. (2012). 'Yang baku' dan 'tak baku'. [Online]. Diakses dari https://www.kompasiana.com/pramanahadi/550da59ea33311781b2e3dce/yang-bakudan-tak-baku

Hidayat, N.R. (2018). Pengembangan motif ukiran rumah gadang untuk motif kain: revitalisasi dan pengembangan industri kreatif. Jurnal Ilmiah Lingua Idea. 9(1), 13-22. Diakses dari http://repo.unand.ac.id/9113/

Isnan, H. \& Rohmiyati, Y. (2016). Pelestarian pengetahuan seni ukir masyarakat Minangkabau. Jurnal Ilmu Perpustakaan, 5(1), 1-12. Diakses dari https://ejournal3.undip.ac.id/index.php/jip/article/view/15316

Khairuzzaky. (2018). Kajian struktur ragam hias ukiran tradisional Minangkabau pada Istano Basa Pagaruyung. Jurnal Titik Imaji, 1(1), 54-67. Diakses dari https://journal.ubm.ac.id/index.php/titik-imaji/article/view/1090

Usman, I. (1980). Seni ukir tradisional Minangkabau dalam konteks adat istiadat. Padang: Universitas Andalas. 
Sanyoto, S.E. (2006). Metode perancangan komunikasi visual periklanan. Yogyakarta: Dimensi Press.

Vannisa. (2018). Kebudayaan Sumatera Barat lengkap beserta gambar dan penjelasannya. [Online]. Diakses dari https://perpustakaan.id/kebudayaan-sumatera-barat/

Waluyanto, H.D. (2005). Komik sebagai media komunikasi visual pembelajaran. Jurnal Desain Komunikasi Visual Nirmana, 7(1), 45-55. Diakses dari http://nirmana.petra.ac.id/index.php/dkv/article/view/16441/16433 